\title{
Phytotoxic Effects of Two Biochars Derived from Wood Chip and Sewage Sludge: Salt Stress and Toxic Compounds Tests
}

\author{
Laila Bouqbis $^{1 *}$, Claudia Irene Kammann ${ }^{2}$, Moulay Cherif Harrouni ${ }^{3}$, Salma Daoud ${ }^{4}$, \\ \& Hans Werner Koyro ${ }^{2}$ \\ ${ }^{1}$ Polydisciplinary Faculty, Ibn Zohr University, Taroudant, Morocco, \\ ${ }^{2}$ Department of Plant Ecology, Justus-Liebig-University, Giessen,Germany \\ ${ }^{3}$ Hassan II Agronomic and Veterinary Institute, Agadir, Morocco \\ ${ }^{4}$ Faculty of Sciences, Ibn Zohr University, Agadir, Morocco, \\ *Corresponding author. E-mail address: bouqbisl@yahoo.fr
}

\begin{abstract}
Biochar is attracting recently growing interest for its potential use as a carbon sequestration agent and as a soil amendment for improved agricultural productivity. Thus converting biomass wastes into biochar may be considered as a tool for waste disposal and recycling option. However many of the previous results are highly variable and dependent mainly on the initial soil properties and biochar characteristics. In addition, biochar applied to soils should be free of toxic substances before any future large-scale application. In this study, two biochars: Biochar I (BC I) derived from wood chip and biochar III (BC III) derived from sewage sludge are used and their physical and chemical properties are characterized. The second part of this study focused on the effects these two biochars have on germination of salad (test for salt stress) and barley (test for toxic substances). Our results showed that the two biochars have some unique properties compared to the soil, such as high electrical conductivity (EC), high content of $\mathrm{K}, \mathrm{Na}$ and $\mathrm{Mg}$, low content of heavy metals. However, BC III compared to BC I and soil has an acidic $\mathrm{pH}$ and high content of $\mathrm{Ca}$ and $\mathrm{Mg}$. Concerning the two phytotoxic tests, no negative effects of the two biochars on both salad and barley germination have been revealed which provide a preliminary indication that they could be safely used for agriculture. When they are used in mixture with sandy soil, BC I and $B C$ III increased the water holding capacities but the most important value was observed for BC I. Collectively, it is essential to characterize biochar properties prior to selecting a particular char for a specific application in agriculture.
\end{abstract}

Keywords: Biochar, salt stress test, toxic substances test, germination, water holding capacity.

\section{Introduction}

Biochar is defined as the carbon-rich product when biomass is heated in a closed container with little or no available air at relatively low temperatures $\left(<700{ }^{\circ} \mathrm{C}\right)$ (Lehmann and Joseph, 2009). It is attracting recently growing interest for its potential use as a carbon sequestration agent and as a soil amendment for improved agricultural productivity (Lehmann et al., 2006; Shackley et al., 2013; Smith, 2016). Some studies have shown that the addition of biochar to soils resulted in increased aboveground productivity, crop yield, soil microbial biomass, rhizobia nodulation, plant $\mathrm{K}$ tissue concentration, soil phosphorus (P), soil potassium (K), total soil nitrogen $(\mathrm{N})$, and total soil carbon (C) compared with control conditions (Biederman and Harpole, 2013; Smider and Singh, 2014; Zhang et al., 2016). Thus using the biochar as a soil amendment returns most of nutrients to the soils from which they came (Laird et al., 2009).

The physical and chemical properties of biochars derived from different sources of feedstock can vary tremendously leading to the high variability observed in terms of their effects on soil fertility (Sun et al., 2014; Nansubuga et al., 2015). In addition to the many sources of feedstock, the thermal profile and the geographic variations in soil type and climate are some of the chief sources of variability when looking to benefits of biochar as a soil amendment (Wang et al., 2016). Thus, selecting a particular biochar for a specific application will depend on the initial soil properties and biochar characteristics.

However, the use of biochar is not without its critics. Research shows that biochar can contain dangerous inorganic contaminants and organic ones as well as dioxins and furans (Hale et al., 2012; Oleszczuk et al., 2013; Buss et Mazek, 2014; Kołtowski and Oleszczuk, 2015). Furthermore, during the pyrolysis process that generates biochar, heating causes some nutrients to volatilize, especially at the surface of the material (Cao et al., 2014; 
Buss et Mazek, 2014). These volatile organic compounds tend to form cyclic, aromatic molecules as pyrolysis temperature increases (Yargicoglu, 2015). In the case of high levels of contaminants there is a risk of their uptake by plants or migration down the soil profile to ground-waters. This may have negative effects on both the environment and living organisms (Kołtowski and Oleszczuk, 2015). Thus, biochar applied to soils should be free of toxic substances before any future large-scale application.

In this study, two biochars: biochar I (BC I) derived from wood chip and biochar III (BC III) derived from sewage sludge (at 75\% dry weight (dw)) are used and their physical and chemical properties are characterized. We also investigated the effects these two biochars have on germination of salad (Lactuca sativa L.) and barley (Hordeum vulgare). Test procedures are adapted from Busch et al., 2012.

\section{Materials and Methods}

\subsection{Soil, Peat and Biochar analysis}

All physical and chemical analysis were performed in the Hassan II Agronomic and Veterinary Institute (IAV) soil science laboratory. The $\mathrm{pH}$ and electrical conductivity (EC) were both measured in water extracts with standard electrodes (Blakemore et al., 1987).

For chemical analysis, the total concentration of $\mathrm{Na}, \mathrm{K}, \mathrm{Ca}$ and $\mathrm{Mg}$ were determined by flame emission spectrophotometer (Van Rast et al., 1999) and $\mathrm{Fe}, \mathrm{Mn}, \mathrm{Zn}$ and $\mathrm{Cu}$ by atomic absorption spectrophotometer (Lindsay and Norvell, 1978) and colorimetrically for $\mathrm{NaNO}_{3}$ and $\mathrm{KH}_{2} \mathrm{PO}_{4}$ (Blakemore et al., 1987; Lachat, 1998a; Lachat, 1998b).

\subsection{Salad Germination Test}

The biochar is mixed with an "inert" fine sand medium using salad germination test (based on ISO-17126), where the germination of a salt-sensitive species (Lactuca sativa L.) is evaluated. Several proportions of biochar and fine sand are mixed following a geometrical dilution. In accordance with the ISO-Norm, the factor 2 is the maximal allowed one, so the series would be: $0 \%, 0.5 \%, 1 \%, 2 \%, 4 \%, 8 \%$ in which zero is the control. For one replicate an amount of fresh weight that equals $100 \mathrm{~g}$ of dry weight was taken out of the whole mixture and filled into a Petri dish. Tap water was added to set up the water content to $85 \%$ of the maximum water holding capacity (WHC). 40 seeds of Lactuca sativa $L$. were evenly sowed, leaving a free space of around $1 \mathrm{~cm}$ to the border of the Petri dishes. They were softly pressed into the substrate. Afterwards $90 \mathrm{~g}$ (dry weight) of coarse sand was distributed on top. The prepared Petri dishes were placed open in a plastic bag with zipper that was bloated and positioned in the green house. For the first $48 \mathrm{~h}$ a black plastic foil covered the dishes.

After 5 days of incubation, the harvest started. We determined the number of germinated seedlings, fresh and dry weight of above ground biomass. The Petri dishes, which still contained the soil mixture were mixed and 25 $\mathrm{g}$ of dry weight were taken. Around $100 \mathrm{ml}$ of water were added. After shaking for an hour by $150 \mathrm{rpm}$, we let the substrate settle down for 30 minutes and determined the $\mathrm{pH}$ and electrical conductivity (EC). All determinations were replicated three times.

\subsection{Barley Germination Test}

Five biochar-peat mixtures have been prepared. We have used small amounts of biochar that equal $0 \%, 1 \%$, $2.5 \%, 5 \%$ and $10 \%$, which means that $1 \%$ describes a mixture of $1 \mathrm{~g}$ dry biochar with $99 \mathrm{~g}$ dry peat. Then we have determined the dry weight and water holding capacity (WHC) of the substrates. To prepare $1000 \mathrm{ml}$ of dry weight for every mixture we have calculated the amount of fresh weight of biochar and peat and the amount of water needed to set the mixture to $60 \%$ of WHCmax. Afterwards we have put some textile/ filter paper into the bottom of our plant pots and split the mixtures into 4 replicates while leaving a bit that is needed to cover the seeds. After sowing in every pot 20 seeds of barely, we have distributed the rest of mixture over the seeds. We have noted the weight of the whole construction (pot + mixture with $60 \%$ of WHCmax + seeds) - this is our first weight. We Placed the pots randomly in the greenhouse.

Everyday, we took the weight of pots and we calculated the difference to the first weight and we adjust it by adding tap water. We determined the consumption of water (by evapo-transpiration) and together with the produced biomass the water use efficiency (WUE). 9 days later, germination rate, biomass fresh weight, dry weight, water content and WUE were determined. 


\subsection{Statistics}

For salad and barley germination tests, effects of different biochar additions on all replicated measurements were tested via one-way analysis of variance (ANOVA). Significance of differences among treatment groups was determined with the Tukey test. A result was considered significant at $p<0$, 05. All statistical tests were performed with SigmaPlot (Systat Inc., Chicago, IL, USA).

\section{Results and Discussion}

\subsection{Soil, Peat and Biochars Properties}

TABLE I: Properties of soil, peat and biochars used in experiment

\begin{tabular}{|c|c|c|c|c|}
\hline & Soil & Peat & Biochar I & Biochar IIl \\
\hline $\mathrm{pH}$ & 7,93 & 5,81 & 9,8 & 6,74 \\
\hline $\mathrm{EC}\left(\operatorname{milliS~} \mathrm{cm}^{-1}\right)$ & 0,48 & 0,94 & 1,25 & 1,51 \\
\hline $\mathrm{K}(\mathrm{ppm})$ & 7,11 & 78,26 & 521,73 & 53,8 \\
\hline $\mathrm{Na}(\mathrm{ppm})$ & 3,47 & 257,94 & 46,54 & 75,7 \\
\hline $\mathrm{Ca}(\mathrm{ppm})$ & 34,09 & 190,9 & 0,61 & 395,45 \\
\hline $\mathrm{Mg}(\mathrm{ppm})$ & 222,89 & 1191,58 & 1303,73 & 1584,11 \\
\hline $\mathrm{Fe}(\mathrm{ppm})$ & 9,07 & 0 & 0 & 0 \\
\hline Mn (ppm) & 7,7 & 0,14 & 0,083 & 0,41 \\
\hline $\mathrm{Cu}(\mathrm{ppm})$ & 1,3 & 0,06 & 0 & 0,032 \\
\hline $\mathrm{Zn}(\mathrm{ppm})$ & 0,42 & 0,04 & 0,0042 & 0,034 \\
\hline $\mathrm{NaNO}_{3}(\mathrm{ppm})$ & 100 & 133,33 & 100 & 100 \\
\hline $\mathrm{KH}_{2} \mathrm{PO}_{4}(\mathrm{ppm})$ & 1 & 2,33 & 0,46 & 0,16 \\
\hline
\end{tabular}

Several studies demonstrated that the environmental function of biochar in soil vary depending on the physical and chemical characteristics of the biochar which depend on feedstock used in the production of biochar and production conditions (Smider and Singh, 2014; Sun et al., 2014; Nansubuga et al., 2015).

In this study, the physical and chemical properties of BC I and BC III compared to other media are shown in table I. The two Biochars showed some unique properties compared to the soil, such as high EC, high content of $\mathrm{K}, \mathrm{Na}, \mathrm{Mg}$ and low content of heavy metals. Depending on the pyrolysis conditions and the nature of the feedstock, different $\mathrm{pH}$ values ranging in $\mathrm{pH}$ from 4 to 13 can be reached (Chan et al., 2008; Wang et al., 2016). In this sense, BC I and BC III resulted in the same pH range. The alkaline nature of biochar I has been reported to be useful to increase the $\mathrm{pH}$ of acidic soils. However, BC III showed some unique properties compared to biochar I and soil such as acidic $\mathrm{pH}$ and high content of $\mathrm{Ca}$ and $\mathrm{Mg}$.

The EC value was higher for two biochars compared to the soil. Previous research reported that added biochar with high EC value into soil with low EC value (indicating its low salinity) increased EC of soil (Chan et al., 2008; Sigua et al., 2016). Thus, we would expect that the EC of the soil $(0,48 \mathrm{mS} / \mathrm{cm})$ would increase with biochar application. Given the high nutrient content of the biochar I and biochar III used in this study, a significant positive effect on plant growth especially in the sandy soil would be expected.

\subsection{Salad Germination Test}

Biochar use as soil conditioner is currently an important topic of research because of the benefits to crop yield and to the soil (Smider and Singh, 2014). However, salinity and alkalinity of biochar are negative characteristics for its use as growth media. It can inhibit growth, creating phytotoxic effects through low external water potentials, ion toxicity and ion imbalance (Gong et al., 2011). To test for salt stress, salad germination test is selected in this study where the biochar is mixed with an inert finesand medium; but where the germination of a salt-sensitive species (Lactuca sativa L.) is evaluated. Thus, negative effects at high application levels on salad germination may indicate high ash contents but no harmful substances.

Our results, as shown in Fig. 1a, revealed a positive effect of BC I and BC III on germination rate of salad in all of the biochar treatments except for the mixture with $4 \%$ of BC I in which a non-significant decrease was 
observed. In other words, the biochar application increased the germination rate by $17 \%$ and $9 \%$ for BC I and BC III respectively indicating that the most important value was observed for BC I. A positive effect was also observed for the more sensitive parameter to biotoxic substances in biochar: fresh weight of seedlings (Fig. 1b and Fig. 1c). Even when biochar contributed with $8 \%$ volume of the germination mixture, no negative effect was observed. In other words, the biochar application increased the fresh weight per petri dish by $98 \%$ and $54 \%$ for BC I and BC III respectively indicating that the most important value was observed for BC I.

Moreover, the biochar application increased the fresh weight per plant by $70 \%$ and $48 \%$ for BC I and BC III respectively. We can explain our results (increasing germination rate, fresh weight of biomass, EC value) for the two biochars used in this study by the presence of more water soluble nutrients in the mixture which is mainly originated from biochar (Lehmann and Rondon, 2006; Biederman and Harpole, 2013; Zhang et al., 2016). Thus, the mixing of biochar and soil would facilitate cation retention in the soil. However, the amount of BC III should be calculated carefully before being added into acidic soil to prevent any soil problems and nutrient imbalances.

(a)
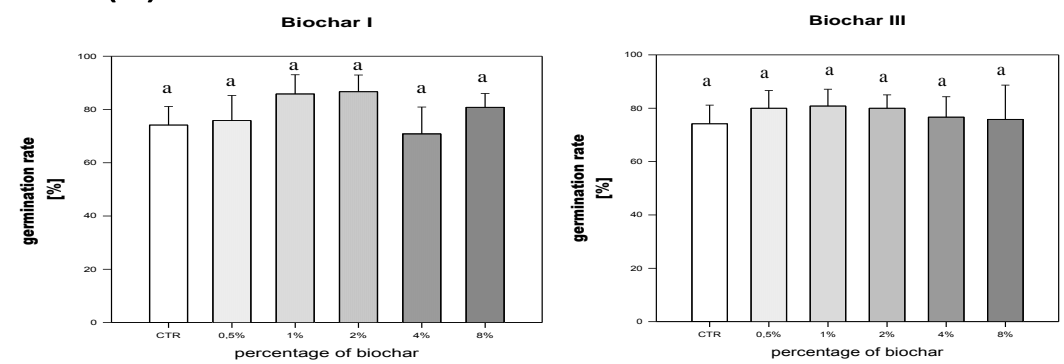

(b)
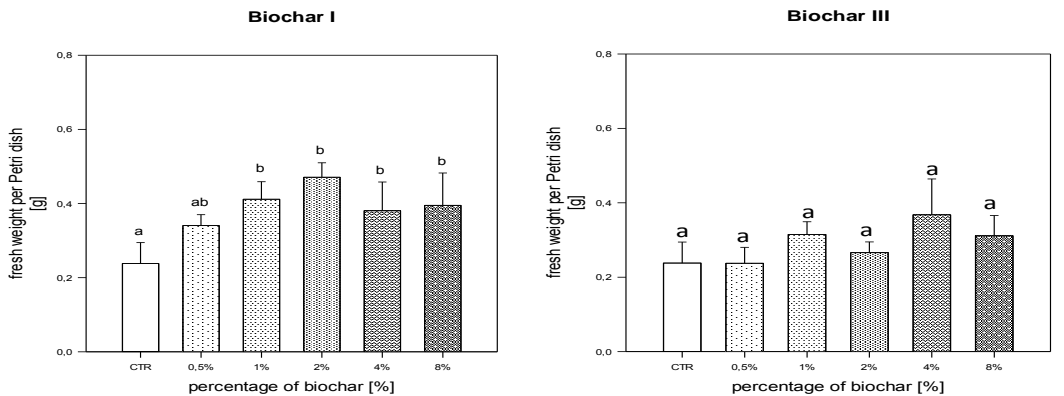

(c)
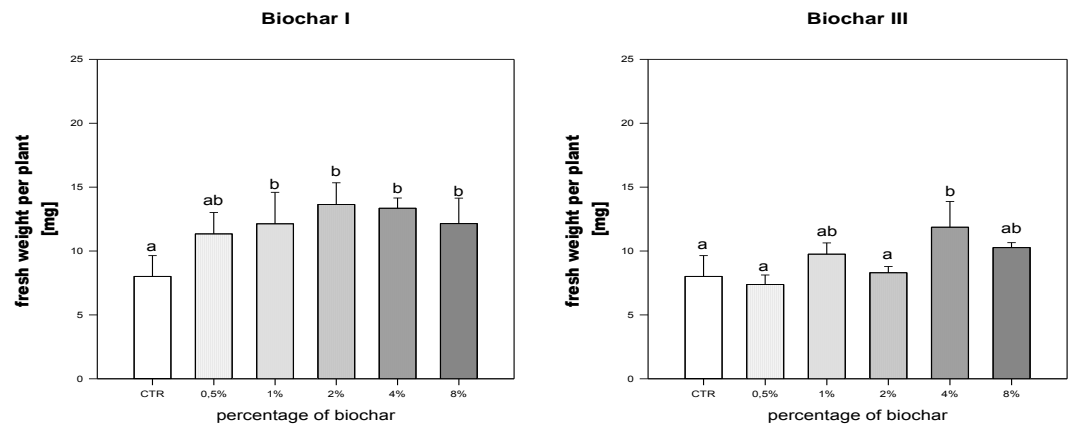

Fig. 1: Salad germination test results: (a): germination rate, (b): fresh weight per petri dish, (c): fresh weight per plant of three repeated test runs. The graphs present mean values and error bars present the standard deviation of the mean $(n=3)$. Different letters indicate significant differences (oneway analysis of variance, ANOVA) between different mixtures with biochar and the control.

The application of BC I at increasing rate significantly increased the $\mathrm{pH}$ before and after planting (Fig. 2a and Fig. $2 \mathrm{~b}$ respectively). The alkaline nature of biochar has been reported to be useful to increase the $\mathrm{pH}$ of acidic soils which is in line with our result. The high $\mathrm{pH}$ of $\mathrm{BC}$ I revealed that a significant portion of the nutrient salts 
sequestered in biomass feedstock were concentrated during the pyrolysis process. The same results have previously been published (Biederman and Harpole, 2013; Jung et al., 2016). The application of BC III at increasing rate decreased the $\mathrm{pH}$ after planting which can be explained by the acidic nature of biochar.

In addition, the two biochars application at high level increased significantly the EC of mixture before and after planting (Fig. 2c and Fig. 2d), which can be explained by the high content of more major nutrients in the two biochars used in this study. Collectively, our results indicate that the two biochars used would be beneficial to soil but before any large scale application, it is necessary to determine which biochar materials are best suited for application and at which rates to specific soils.

For BC I the water holding capacities were 0,$30 ; 0,33$ and $0,51 \mathrm{gH} 2 \mathrm{O}$ per $\mathrm{g}$ soil (dry weight) in $0 \% ; 0,5 \%$ and $8 \%$ biochar-sand mixtures, respectively. For BC III, the water holding capacities were 0,2979; 0,2766 and $0,3037 \mathrm{gH} 2 \mathrm{O}$ per $\mathrm{g}$ soil (dry weight) in $0 \% ; 0,5 \%$ and $8 \%$ biochar-sand mixtures, respectively. The biochar application increased the WHC by $70 \%$ and $2 \%$ for BC I and BC III respectively indicating that the most important value was observed for BC I. An increase in water holding capacity has also been reported for wet conditions with biochar application (Cao et al., 2014; Wang et al. 2016).

(a)

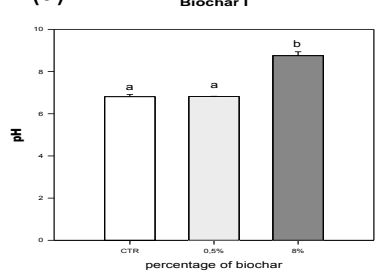

(b)

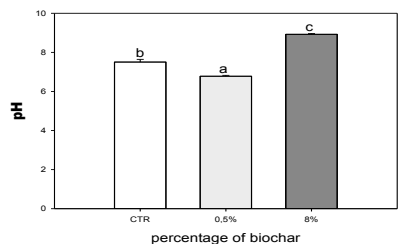

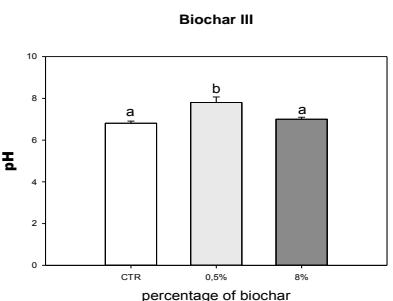

Biochar III

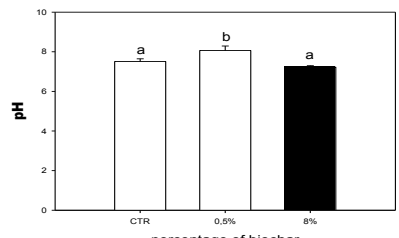

(c)

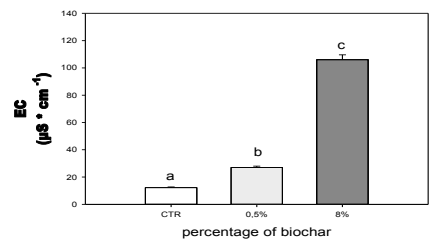

(d)

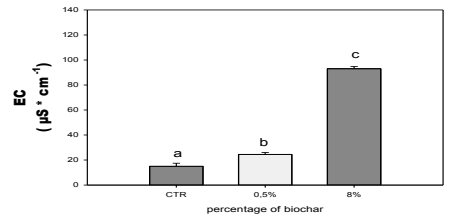

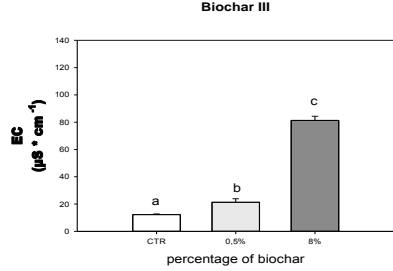

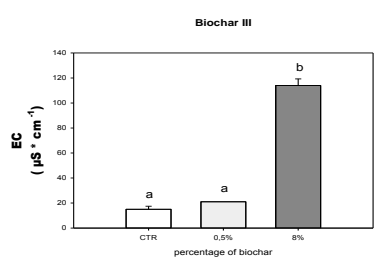

Fig. 2: Effect of biochar application on $\mathrm{pH}$ and $\mathrm{EC}$ before and after germination of salad. (a): $\mathrm{pH}$ values before planting, (b): $\mathrm{pH}$ values after planting, (c): EC values before planting, (d): EC values after planting of two repeated test runs. The graphs present mean values and error bars represent the standard deviation of the mean $(n=3)$. Different letters indicate significant differences (oneway analysis of variance, ANOVA) between different mixtures with biochar and the control.

\subsection{Barley Germination Test}

Biochars can contain toxic compounds produced during the process of pyrolysis or accumulated in the feedstock used in the production of biochars (Hale et al., 2012; Oleszczuk et al., 2013; Buss et Mazek, 2014; Kołtowski and Oleszczuk, 2015). The content of such compounds in biochar can sometimes be very high, which may create the risk of their uptake by plants or migration down the soil profile to groundwaters (Kołtowski et al., 2015).

To test for toxic substances, barley germination test was selected where biochar was mixed into an organic medium (unfertilized peat substrate) and the plant was not sensitive to salt stress. Thus, negative effects at high application levels on barley germination may indicate potential toxic effects of harmful substances produced during the process of pyrolysis.

In this study, the germination results of different mixtures (peat-biochar) were compared with those of control (infertilized peat, $0 \%$ biochar) where the fresh/dry weight was the most sensitive parameter to indicate negative effect of biochar on seedlings. In all biochar treatments $(1 \%, 2.5 \%, 5 \%$ and $10 \%$ biochar-peat mixture), no negative effect of the two biochars on germination rate of barley was revealed (Fig. 3a).

The same result was observed for the more sensitive parameters to biotoxic substances in biochar: fresh and dry weight of seedlings (Fig. 3b and Fig. 3c) except for BC III in which a non-significant decrease in dry weight was observed even with the lowest application rate. In other words, biochar application increased the fresh weight by $7 \%$ and $1 \%$ for BC I and BC III respectively indicating that the most important value was observed 
for BC I. Furthermore, biochar application increased the dry weight by $6 \%$ for BC I. The low increases of biomass with biochar I application could be due to much shorter test (9 days).

Regarding the chemical properties of BC I compared to the peat (high $\mathrm{EC}$, high content of $\mathrm{K}, \mathrm{Mg}$ and low content of heavy metals as presented in table I) the observed increases, even low, in fresh and dry weight of biomass could be the results of high level of water soluble nutrients and the absence low content of harmful substances in mixture with biochar application. Thus biochar I could provide the potential for a better plant growth. For BC III, the end use of this biochar will depend on the initial soil properties and biochar characteristics.

(a)

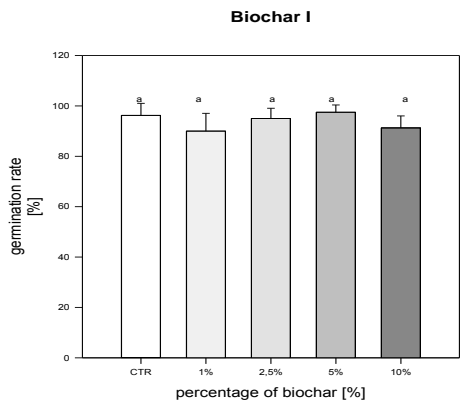

(b)

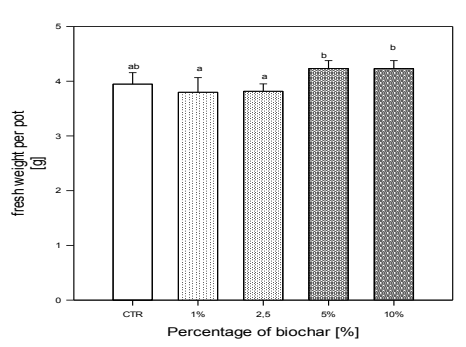

(C)

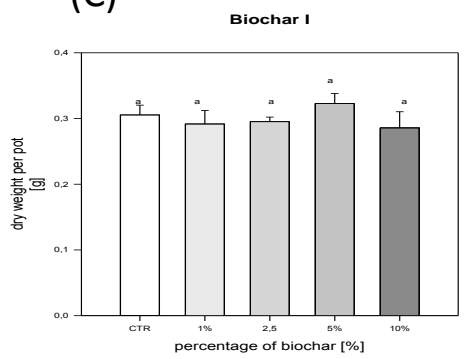

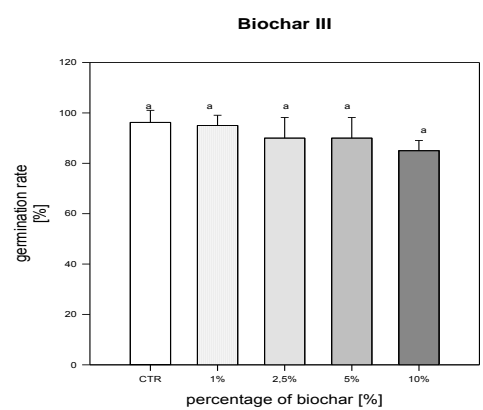
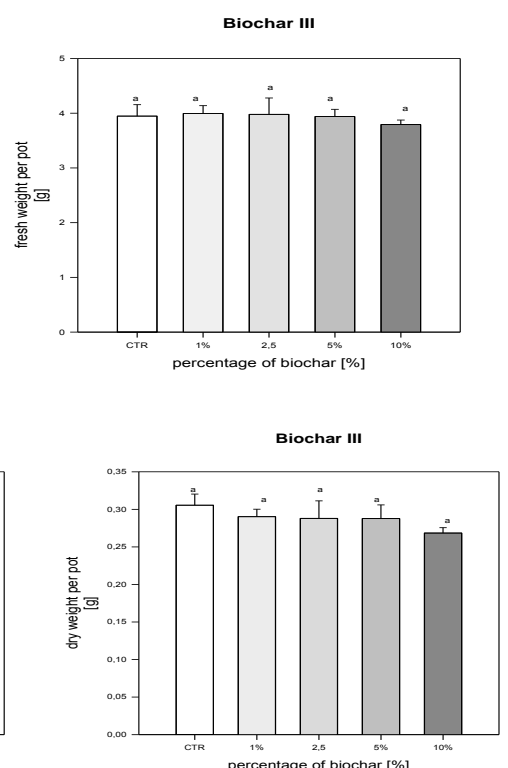

Fig. 3: Effect of two biochars on germination of barley. (a): germination rate, (b): fresh weight per plant and (c): dry weight per plant for four repeated test runs. The graphs present mean values and error bars present the standard deviation of the mean $(n=4)$. Different letters indicate significant differences (oneway analysis of variance, ANOVA) between different mixtures with biochar and the control

The relative chlorophyll content was measured with five replicated measurements on three leaves per plant using a SPAD 502 device (Minolta, USA). Fig. 4a shows the SPAD values in the two biochars test compared to the control. The results indicate that BC I decreased the SPAD value even at a mixture with $1 \%$ biochar (Fig. 4a) but none of the biochar additions resulted in a significant decrease while a small but non-significant increase was observed with biochar III at 2,5\% volume biochar addition.

Furthermore, in all biochar treatments $(1 \% ; 2,5 \% ; 5 \%$ and $10 \%$ biochar-peat mixture), no negative effect of the two biochars on water content was revealed (Fig. 4b). In other words, biochar application increased the water content by $8 \%$ and $2 \%$ for BC I and BC III respectively indicating that the most important value was observed for BC I. As found in the present study, the improvement of water retention capacities after biochar addition have previously been observed (Cao et al., 2014; Obia et al., 2016) and reported to be due to its porous nature (Yu et al., 2016). 
BC III had also a positive effect on water use efficiency (Fig. 4c). It's application increased the WUE by $8 \%$ which is in line with the observations of Sun and Lu, 2014; Obia et al., 2016 which have reported that the use of biochar as a soil amendment is anticipated to increase both nutrient and water use efficiency and thereby crop productivity where there is less drainage. This was not the case for BC I in which biochar application decreased the water use efficiency.

(a)
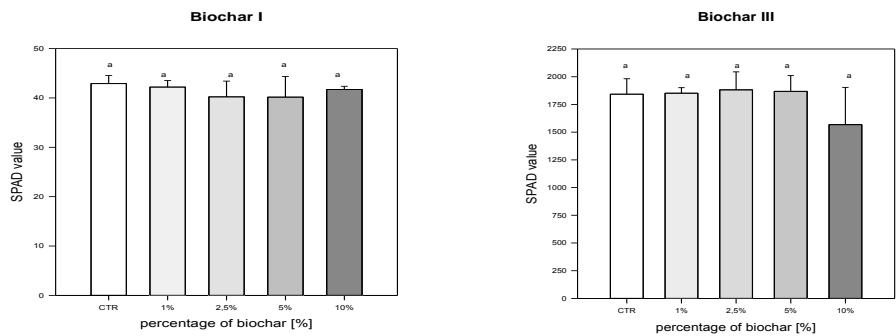

(b)
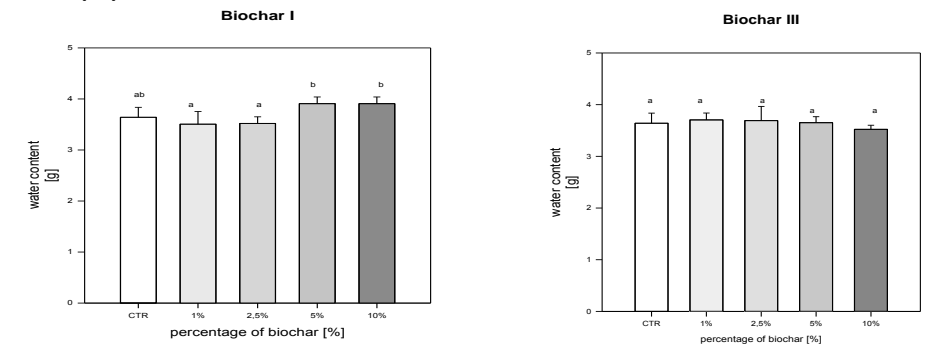

(c)
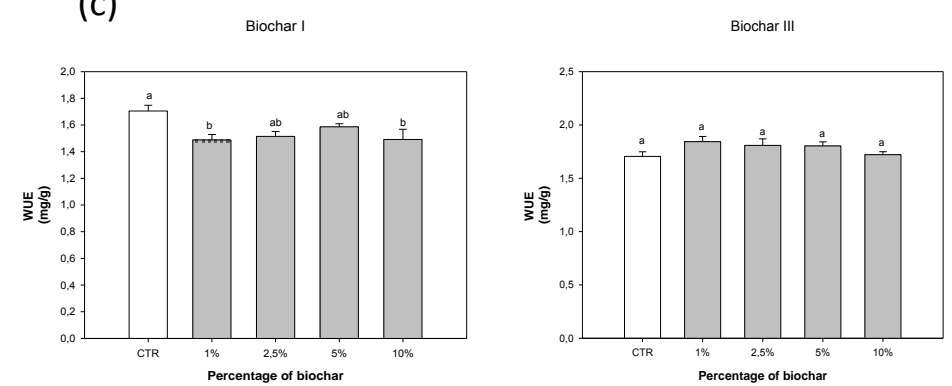

Fig. 4: Effect of biochars on SPAD values, water content and water use efficiency after 9 days of germination of barley. (a): SPAD values, (b): water content, (c): water use efficiency for four repeated test runs. The graphs present mean values and error bars present the standard deviation of the mean $(n=4)$. Different letters indicate significant differences (oneway analysis of variance, ANOVA) between different mixtures with biochar and the control.

\section{Conclusion}

Biochar, the $\mathrm{C}$ rich product produced during the pyrolysis of biomass, is well documented to improve soil structure and crop productivity. However, the physical and chemical properties of biochars derived from different sources of feedstock can vary leading to the high variability observed in terms of their effects on soil fertility. Yet, toxic compounds produced during the process of pyrolysis and salinity of biochar are negative characteristics for its use as growth media. Thus, biochar applied to soils should be free of toxic substances and salt effect.

In this study, the physical and chemical characheristics of BC I and BC III showed some unique properties compared to the soil, such as high $\mathrm{EC}$, high content of $\mathrm{K}, \mathrm{Na}$ and $\mathrm{Mg}$, low content of heavy metals. However, BC III compared to biochar I and soil has an acidic $\mathrm{pH}$ and high content of $\mathrm{Ca}$. The water holding capacities (WHC) of biochar-sand mixtures increased with increasing biochar application and the most important value 
was observed for BC I. Collectively, the use of BC I and BC III as a soil amendment will be anticipated to increase both nutrient and water retention.

The results obtained from the two phytotoxicity tests (test for salt stress and test for toxic substances) revealed no negative effect of BC I and BC III which provide a preliminary indication that they could be safely used for agriculture. But, detailled research in long term experiments will be a natural next step.

\section{Acknowledgment}

This work has been funded by the Department of Plant Ecology, Justus-Liebig-University, Giessen, Germany and the Hassan II Agronomic and Veterinary Institute, Agadir, Morocco. Laila Bouqbis would like to acknowledge Dr. Nicole Messerschmidt for her contribution to experimental work.

\section{References}

[1] J. Lehmann and S. Joseph, Biochar for Environmental Management: Science and Technology, 1st ed. Earthscan Ltd., London, 2009, ch. 1, pp. 1-12. ISBN: 978-1-84407-658-1.

[2] J. Lehmann, J. Gaunt, and M. Rondon, "Bio-char sequestration in terrestrial ecosystems- a review," Mitigation and adaptation strategies for global change, vol. 11, pp. 403-427, 2006.

[3] S. Shackley, S. Sohi, R. Ibarrola, J. Hammond, O. Mašek, P. Brownsort, A. Cross, M. Prendergast-Miller, S. Haszeldine, "Biochar, tool for climate change mitigation and soil management," In: Lenton, T., Vaughan, N. (Eds.), Geoengineering Responses to Climate Change, Springer, New York, pp. 73-140, 2013.

[4] P. Smith, "Soil carbon sequestration and biochar as negative emission technologies," Journal of Global change biology, Vol. 22, pp. 1315-1324, 2016.

[5] L. A. Biederman, W.S. Harpole, "Biochar and its effects on plant productivity and nutrient cycling: A meta-analysis, " GCB Bioenergy, vol. 5, pp. 202-214, 2013.

[6] B. Smider, B. Singh, "Agronomic performance of a high ash biochar in two contrasting soils," Agriculture Ecosystems and Environment, vol. 191, pp. 99-107, 2014.

[7] D. Zhang, G. Pan, G. Wu, G. Wanjiru Kibue, L. Li, X. Zhang, J. Zheng, J. Zheng, "Biochar helps enhance maize productivity and reduce greenhouse gas emissions under balanced fertilization in a rainfed low fertility inceptisol," Chemosphere, vol. 142, pp. 106-113, January 2016.

[8] Y. Sun, B. Gao, Y. Yao, J. Fang, M. Zhang, Y. Zhou, H. Chen, L. Yang, "Effects of feedstock type, production method, and pyrolysis temperature on biochar and hydrochar properties," Chemical Engineering Journal, vol. 240, pp. 574-578, 2014.

[9] I. Nansubuga, N. Banadda, F. Ronsse, W. Verstraete, K. Rabaey, "Digestion of high rate activated sludge coupled to biochar formation for soil improvement in the tropics, "Water Research, vol. 81, pp. 216-222, 2015.

[10] C. T.N. Cao, C. Farrella,, P. E. Kristiansenc, J. P. Rayner, "Biochar makes green roof substrates lighter and improves water supply to plants, " Ecological Engineering, vol . 71, pp. 368-374, 2014.

[11] L.C. Blakemore, P.L. Searle, B.K. Daly, Methods for Chemical Analysis of Soils. New Zealand Soil Bureau Scientific Report 80. 103 p. 1987.

[12] E.Van Rast, M. Verloo, A. Demeyer, J.M. Pauwels, Manual for the Soil Chemistry and Fertility Laboratory. Ed, 1999.

[13] W.L. Lindsay, W.A. Norvell, "Development of a DTPA soil test for zinc, iron, manganese and copper," Soil Science Society of America Journal, vol 42, pp. 421-428, 1978.

[14] Lachat Instruments, Milwaukee, WI, USA, Quik Chem Method, no. 13-107-06-2-D, 1998a.

[15] Lachat Instruments, Milwaukee, WI, USA, Quik Chem Method, no. 13-115-01-1-B, 1998b.

[16] D. A. Laird, R. C. Brown, J. E. Amonette and J. Lehmann, "Review of the pyrolysis platform for coproducing bio-oil and biochar," Biofuels, Bioprod. Bioref. Vol 3, pp. 547-562, 2009.

[17] Y. Wang, L. Zhang, H. Yang, G. Yan, Z. Xu, Ch. Chen, D. Zhang, “ Biochar nutrient availability rather than its water holding capacity governs the growth of both C3 and C4 plants," Journal of Soils and Sediments, vol. 16, Issue 3, pp. 801-810, 2016.

[18] S.E. Hale, J. Lehmann, D. Rutherford, A.R. Zimmerman, R.T. Bachmann, V. Shitumbanuma, A. O’Toole, K.L. Sundqvist, H.P.H Arp, G. Cornelissen, "Quantifying the total and bioavailable polycyclic aromatic hydrocarbons and dioxins in biochars," Environ. Sci. Technol, vol. 46, pp. 2830-2838, 2012. 
[19] P. Oleszczuk, I. Jo_sko, M. Ku_smierz, "Biochar properties regarding to contaminants content and ecotoxicological assessment," J. Hazard. Mater, vol. 260, pp. 375-382, 2013.

[20] W. Buss, O. Masek, "Mobile organic compounds in biochar : A potential source of contamination-Phytotoxic effects on cress seed (Lepidium sativum) germination," Journal of Environmental Management, vol. 137, pp. 111-119, 2014

[21] M. Kołtowski, P. Oleszczuk, "Toxicity of biochars after polycyclic aromatic hydrocarbons removal by thermal treatment," Ecological Engineering, vol. 75, 79-85, 2015.

[22] N. E. Yargicoglu, B. Y. Sadasivam, K. R. Reddy, K. Spokas, "Physical and chemical characterization of waste wood derived biochars," Waste Management, vol. 36, pp. 256-268, 2015.

[23] D. Busch, C. Kammann, L. Grünhage, and Ch. Müller, "Simple Biotoxicity Tests for Evaluation of Carbonaceous Soil Additives: Establishment and Reproducibility of Four Test Procedures," Journal of Environmental Quality vol. 41, pp. 1023-1032, 2012.

[24] K.Y. Chan, L. Van Zwieten, I. Meszaros, A. Downie, S. Joseph, "Using poultry litter biochars as soil amendments," Australian Journal of Soil Research, vol. 46, pp. 437-444, 2008.

[25] G.C. Sigua, J.M. Novak, D.W. Watts, M.G. Johnson, K. Spokas, "Efficacies of designer biochars in improving biomass and nutrient uptake of winter wheat grown in a hard setting subsoil layer," Chemosphere, vol. 142, pp. 176$183,2016$.

[26] X. Gong, L.Chao, M. Zhou, M. Hong, L. Luo, L. Wang, W. Ying, C. Jingwei, G. Songjie, H. Fashui, “ Oxidative damages of maize seedlings caused by exposure toa combination of potassium deficiency and salt stress," Plant Soil, vol. 340, pp. 443-452, 2011.

[27] J. Lehmann, M. Rondon, "Bio-char soil management on highly weathered soils in the humid tropics, " In: Uphoff, N. (Ed.), Biological Approaches to Sustainable. Soil Systems. CRC Press, Boca Raton FL, pp. 517-531, 2006

[28] K.-W. Jung, K. Kim, T.-U. Jeong, K.-H. Ahn, "Influence of pyrolysis temperature on characteristics and phosphate adsorption capability of biochar derived from waste-marine macroalgae (Undaria pinnatifida roots)," Bioresource Technology, vol. 200, pp. 1024-1028, 2016.

[29] A. Obia, J. Mulder, V. Martinsen, G. Cornelissen, T. Børresen, "In situ effects of biochar on aggregation, water retention and porosity in light-textured tropical soils," Soil and Tillage Research, vol. 155, pp. 35-44, 2016.

[30] X. Yu, C. Wu, Y. Fu, P. C. Brookes and S. Lu, "Three-dimensional pore structure and carbon distribution of macroaggregates in biochar-amended soil," European Journal of Soil Science, vol. 67, Issue 1, pp. 109-120, 2016.

[31] F. Sun and S. Lu, "Biochars improve aggregate stability, water retention, and porespace properties of clayey soil," Journal of Plant Nutrition and Soil Science, vol. 177, Issue 1, pp. 26-33, 2014. 